\title{
Thermal resistance of alkaline fused phosphate sludge-based geopolymer mortar
}

\author{
Samira Moukannaa ${ }^{1}$, Ali Nazari ${ }^{2}$, Ali Bagheri ${ }^{3}$, Mohamed Loutou ${ }^{4}$, Rachid Hakkou ${ }^{5}$ \\ ${ }^{1,5}$ LCME, Laboratoire de chimie des Matériaux et d'Environnement, Faculté des Sciences et Techniques, \\ Université Cadi Ayyad, Av. A. Khattabi, B.P.549, 40000 Marrakech, Morocco \\ ${ }^{1,5}$ Materials Science and Nano-engineering Center, Mohammed VI Polytechnic University, \\ Lot 660-Hay Moulay Rachid, Bengurir, Morocco \\ ${ }^{2,3}$ Department of Civil and Construction Engineering, Faculty of Science, Engineering and Technology, \\ Swinburne University of Technology, Hawthorn, Victoria 3122, Australia \\ ${ }^{4}$ Faculté Pluridisciplinaire de Nador, Université Mohammed 1er, B.P. 300, 62700 Selouane, Nador, Morocco
}

\section{E-mail: ${ }^{1}$ samira.moukannaa@um6p.ma (corresponding author)}

\begin{abstract}
The present study investigates the thermal behaviour of phosphate sludge-based geopolymers. Phosphate sludge which is a by-product from phosphate beneficiation processes was activated using the alkaline fusion method to improve the geopolymer activity of this material. Then, the mechanical properties as well as the thermal behaviour of the resulted geopolymer mortar were studied. The effect of sodium hydroxide addition and fusion temperature on the mechanical properties and the thermal behaviour of the geopolymers were assessed using compressive strength tests before and after thermal shock cycles at different temperatures $\left(350,500,650{ }^{\circ} \mathrm{C}\right)$. The mineralogical composition of the fused materials was investigated using XRD measurement and the microstructure of the geopolymer mortars was studied using FTIR. The obtained results showed that $\mathrm{NaOH}$ content as well as the temperature of fusion are essential parameters controlling the structure and the strength of the developed geopolymeric gel. Exposure to elevated temperatures up to $650{ }^{\circ} \mathrm{C}$ induces a decrease in compressive strength between 58 and $71 \%$. However, a further increase in the temperature of exposure till $800{ }^{\circ} \mathrm{C}$ induces a development of compressive strength. Overall, geopolymers with good compressive strength up to $40 \mathrm{MPa}$ could be synthesized in the optimum conditions of fusion: $10 \%$ of $\mathrm{NaOH}$ and $550{ }^{\circ} \mathrm{C}$.
\end{abstract}

Keywords: high-performance materials, cementitious composites, geopolymer, alkaline fusion, thermal resistance.

\section{Introduction}

The valorisation of mine wastes and mine tailing using the geopolymerization technology has attracted scientist's attention recently because of the geopolymer's confinement properties. The main purpose is to explore new utilization of these by-products in order to decrease the environmental impact of their disposal. A variety of mine tailing such as copper (Ahmari, Parameswaran, \& Zhang, 2014; Ahmari \& Zhang, 2013), vanadium (Jiao, Zhang, \& Chen, 2013), tungsten(Pacheco-Torgal, Castro-Gomes, \& Jalali, 2008), gold (Caballero, Sánchez, \& Ríos, 2014), iron (Kuranchie, Shukla, \& Habibi, 2016), coal (Perná, Hanzlíček, \& Šupová, 2014) and phosphate mine tailings (Moukannaa et al., 2018) was used to form geopolymers due to its chemical composition especially its aluminosilicate content. However, the geopolymeric activity of non-calcined material like mine tailings is limited due to its low amorphous phase content. Hence, several methods have been experienced to enhance the geopolymeric reactivity of the raw materials such as mechanical, thermal and chemical activation. Each of these activation methods is acting on different aspects of the material properties (particle size, specific area, crystallinity, mineralogical composition...) (Tchadjie \& Ekolu, 2017). It has been proved that the thermal activation is an efficient method to improve the reactivity of non-calcined materials by increasing their amorphous content (Hairi, Jameson, Rogers, \& MacKenzie, 2015; Zivica, Palou, \& Bágel', 2014). Nevertheless, a combination between the chemical and thermal activations has been evidenced to improve the reactivity of the material by modifying their mineralogical composition, generally, converting some phases into soluble aluminosilicates (Kouamo Tchakoute, Elimbi, Diffo Kenne, Mbey, \& Njopwouo, 2013). 
This method called alkaline fusion consists of mixing the raw material with an alkali source, then heating or calcining at a temperature higher than the melting point of the alkali source to fuse. Then, the resulted material is mixed with an Al source material and activated by sodium silicate or water (Naghsh \& Shams, 2017; Xu, Li, Shen, Zhang, \& Zhai, 2010). The aim of the present study is to investigate the activation feasibility of phosphate sludge from phosphate mine tailings by alkaline fusion and to study the effect of the fusion parameters on the mechanical properties and thermal resistance of the resulted geopolymers.

\section{Materials and methods}

\section{Materials}

Phosphate sludge from the Moroccan phosphate beneficiation plant (OCP-SA) was collected from the hydrocyclones of $40 \mu \mathrm{m}$ during the washing prosses before being mixed with the coarse part of the sludge. The aluminium source used to balance the Al content of the geopolymer mixtures was metakaolin. Sea sand was used as aggregate to prepare the geopolymer mortars.

Figure 1 represent the XRD patterns of the raw materials, metakaolin is mainly consist of amorphous phase, quartz and mullite while phosphate sludge is composed of quartz, fluoroapatite, calcite, dolomite, illite and palygorskite. The chemical composition of the raw materials is presented in Table 1.

Sodium hydroxide pellet and Sodium silicate $\left(24 \% \mathrm{SiO}_{2}, 14 \% \mathrm{Na}_{2} \mathrm{O}\right)$ from Sigma-Aldrich were used in the fusion process and as activator to prepare the geopolymer pastes respectively.

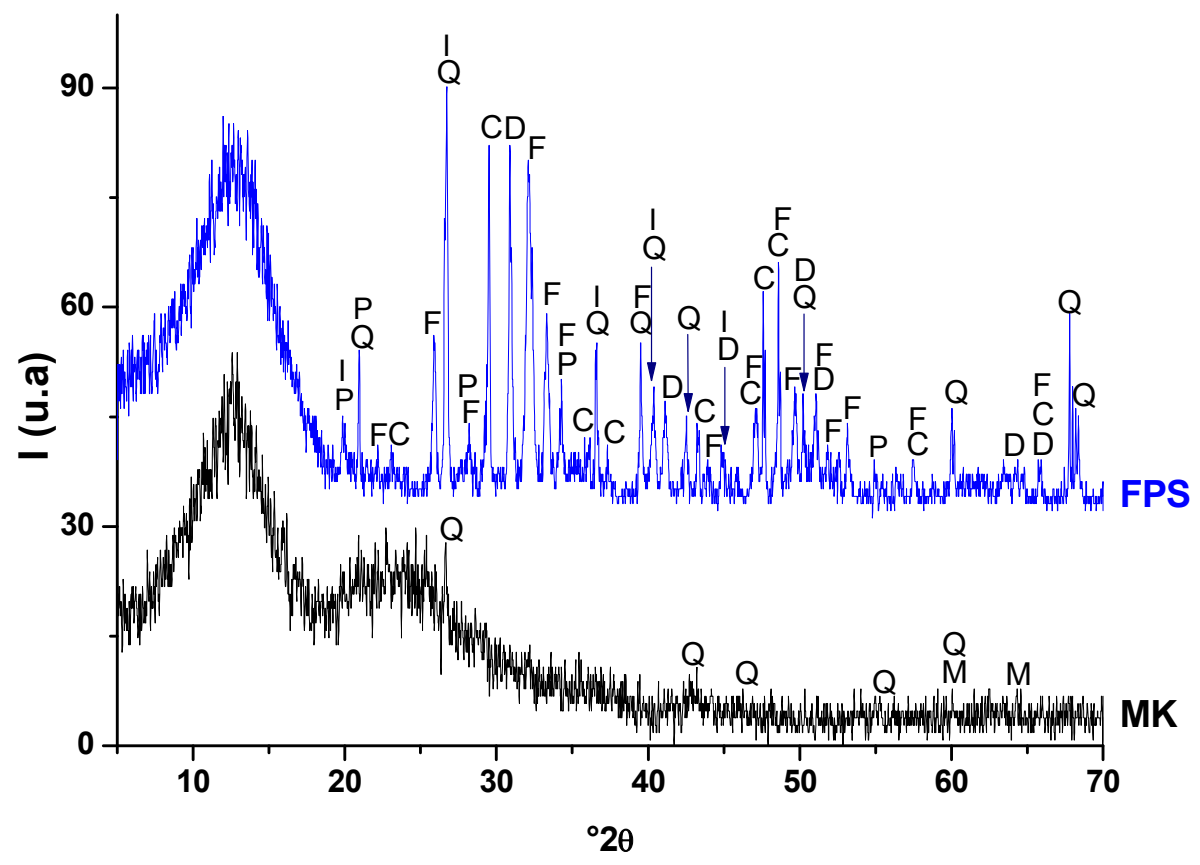

Figure 1. X-ray diffraction patterns of the used raw materials FPS: Fine phosphate sludge (FPS); and MK: Metakaolin. F: Fluorapatite (PDF \# 00-002-0845); Q: Quartz (PDF \# 96-101-1177); C: Calcite (PDF \# 01-072-1651); D: Dolomite (PDF \# 96-900-4935); I: Illite (PDF \# 00-007-0330); P: Palygorskite (PDF \# 00-021-0550); M: Mullite (PDF \# 96-900-5503)

Table 1. Chemical compositions (wt.\%) of the phosphate sludge (FPS) and metakaolin (MK)

\begin{tabular}{|c|c|c|c|c|c|c|c|c|c|}
\hline \multicolumn{10}{|c|}{ Chemical composition (\%) } \\
\hline & $\mathrm{SiO}_{2}$ & $\mathrm{Al}_{2} \mathrm{O}_{3}$ & $\mathrm{Fe}_{2} \mathrm{O}_{3}$ & $\mathrm{MgO}$ & $\mathrm{CaO}$ & $\mathrm{Na}_{2} \mathrm{O}$ & $\mathrm{K}_{2} \mathrm{O}$ & $\mathrm{P}_{2} \mathrm{O}_{5}$ & $\mathrm{LoI}^{\mathrm{a}}$ \\
\hline FPS & 23.5 & 3.56 & 1.52 & 4.17 & 31.1 & 0.54 & 0.45 & 14.1 & 19.3 \\
\hline $\mathrm{MK}$ & 51.8 & 34.2 & 0.5 & 0.1 & 0.1 & 0.6 & - & - & 12.7 \\
\hline
\end{tabular}

a: Loss on Ignition.

\section{Mortar preparation}

The phosphate sludge was mixed with sodium hydroxide $(10,20 \mathrm{wt} \%)$ and calcined using a muffle furnace for $2 \mathrm{~h}$ at different temperatures $\left(550\right.$ and $\left.800{ }^{\circ} \mathrm{C}\right)$. The resulted powder was grounded to pass through a $100 \mu \mathrm{m}$ mesh and mixed with metakaolin $(40 \mathrm{wt} \%)$, then activated with a sodium silicate solution and mixed for 5 min before adding 
the sand with an aggregate to binder ratio of 2 and the activator to solid ratio was fixed at 0.4 . The resulted paste was further mixed for $5 \mathrm{~min}$, then poured into cylindrical molds $(\mathrm{D}=36 \mathrm{~mm}, \mathrm{H}=72 \mathrm{~mm})$, vibrated to eliminate air bubbles and covered by plastic sheets to avoid moisture loss for $24 \mathrm{~h}$. The geopolymer samples were then demolded and cured at $60^{\circ} \mathrm{C}$ for $4 \mathrm{~h}$. a control sample was prepared following the same ratios without fusion in order to evidence the fusion significance on the resulted materials. (see Table 2).

Table 2. Composition of the geopolymers prepared from fused phosphate sludge and metakaolin

\begin{tabular}{|c|c|c|c|c|c|c|c|}
\hline Code & Fusion $\mathrm{T}^{\circ}$ & Sand/ CM & $\% \mathrm{SH}$ & $\% \mathrm{MK}$ & SS/solid & Water & liq/Sol \\
\hline $\mathrm{F} 0$ & $28^{\circ} \mathrm{C}$ & 2 & $20 \%$ & 40 & 0.4 & 84 & 0.5 \\
\hline $\mathrm{F} 1$ & $800^{\circ} \mathrm{C}$ & 2 & $10 \%$ & 40 & 0.4 & 84 & 0.5 \\
\hline $\mathrm{F} 2$ & $550^{\circ} \mathrm{C}$ & 2 & $10 \%$ & 40 & 0.4 & 84 & 0.5 \\
\hline $\mathrm{F} 3$ & $800^{\circ} \mathrm{C}$ & 2 & $20 \%$ & 40 & 0.4 & 84 & 0.5 \\
\hline $\mathrm{F} 4$ & $550^{\circ} \mathrm{C}$ & 2 & $20 \%$ & 40 & 0.4 & 84 & 0.5 \\
\hline
\end{tabular}

\section{Analysis methods}

The mineralogical composition of the starting materials and the geopolymer samples were obtained using a Bruker D8 Advance X-ray diffractometer operating with $\mathrm{Cu} \mathrm{K \alpha}$ radiation. A continuous scan mode was used in the range $2 \theta=5^{\circ}-70^{\circ}$ with a step size of $0.02^{\circ}$ and a scanning step of $0.01^{\circ}$. The elemental analysis of the raw materials was performed by X-Ray Fluorescence spectroscopy technique using a Bruker S8 Tiger WD-XRF. The microstructural observations by SEM and EDS analysis were performed via a Guemini apparatus with accelerating voltage being of 20 kV. A Perkin Elmer® Frontier spectrophotometer equipped with an Attenuated Total Reflectance (ATR) accessory and operating in the range of $4000-400 \mathrm{~cm}^{-1}$ was used to perform the FTIR measurements. The mechanical properties of the synthesized geopolymer mortars were evaluated by compressive strength measurement and conducted using a Technotest electrohydraulic machine with a rate of $0.25 \mathrm{~mm} / \mathrm{min}$. The compressive strength $\left(\mathrm{N} / \mathrm{mm}^{2}\right) \mathrm{was}$ calculated by dividing the maximum load applied to each sample by the area of its cross-section. The error was obtained by dividing the standard deviation of three samples' compressive strengths by the square of three. The thermal stability of the geopolymer mortars was assessed by measuring the compressive strength of the mortars after being exposed to different temperatures $\left(350,500,650{ }^{\circ} \mathrm{C}\right)$ for $4 \mathrm{~h}$ and a thermal shock at ambient temperature, the microstructure of the treated mortars was analyzed by SEM.

\section{Results and discussion}

The results of compressive strength exposed in Figure 2 shows that the alkaline fusion method used to activate the phosphate sludge was efficient in the improvement of the sludge geopolymeric reactivity. This is evidenced by the higher compressive strength of the fused sludge-based geopolymers in comparison with the control sample. The effect of the $\mathrm{NaOH}$ content is strongly correlated to the temperature of fusion. At $800{ }^{\circ} \mathrm{C}$, the increase of $\mathrm{NaOH}$ lead to a compressive strength raise which is generally expected because of the increase of the aluminosilicate dissolution rate (Tchadjié et al., 2015). At $550{ }^{\circ} \mathrm{C}$, the addition of sodium hydroxide hinders the development of the sample's strength probably because of alkali excess. The difference in behavior toward $\mathrm{NaOH}$ addition between the samples fused at 550 and $800{ }^{\circ} \mathrm{C}$ could be explained by the fact that the fusion at elevated temperatures induce consumption of more $\mathrm{NaOH}$ that is engaged in the formation of Na-rich phases (Ke, Bernal, Ye, Provis, \& Yang, 2015). The optimum fusion parameters exhibiting the higher compressive strength were found at the minimum of $\mathrm{NaOH} 10 \mathrm{wt} \%$ and at the lower temperature of fusion $550^{\circ} \mathrm{C}$.

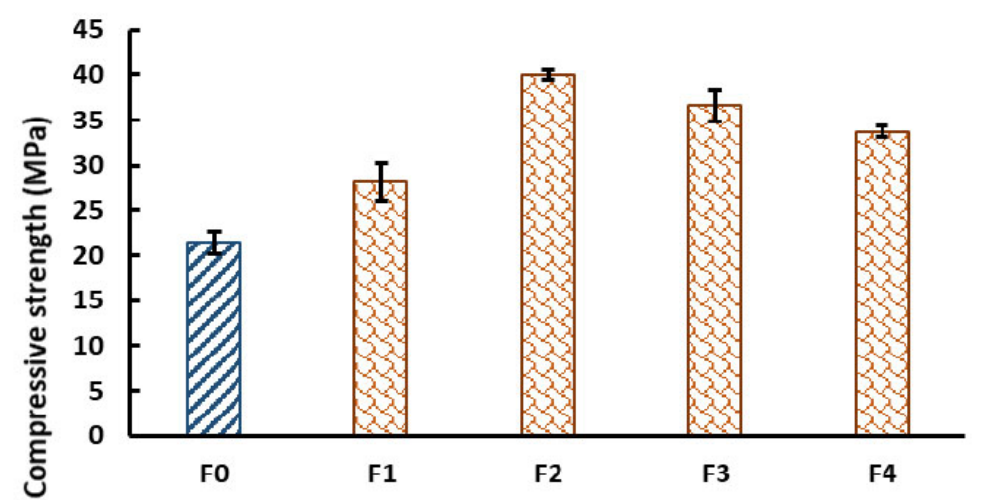

Figure 2. Compressive strength of the control sample F0 and the fused phosphate sludge geopolymers at 28 days 
Figure 3 illustrates the mineralogical composition of geopolymer samples. The amorphous hump between 20 and $40^{\circ} 2$ is characteristic of the geopolymeric phase. The results show the persistence of some original crystalline phases such as quartz which is inert below alkaline conditions. The fluorapatite and calcite phases persisted also but their quantities diminished evidencing their partial participation to the geopolymerization reaction. In addition, some new crystalline phases were formed such as sodium calcium silicate, berlinite $\left(\mathrm{AlPO}_{4}\right)$ and cristobalite. These new formed phases were a result of the interaction between the decomposed original phases during the fusion, the available $\mathrm{Na}^{+}$and sodium silicate.

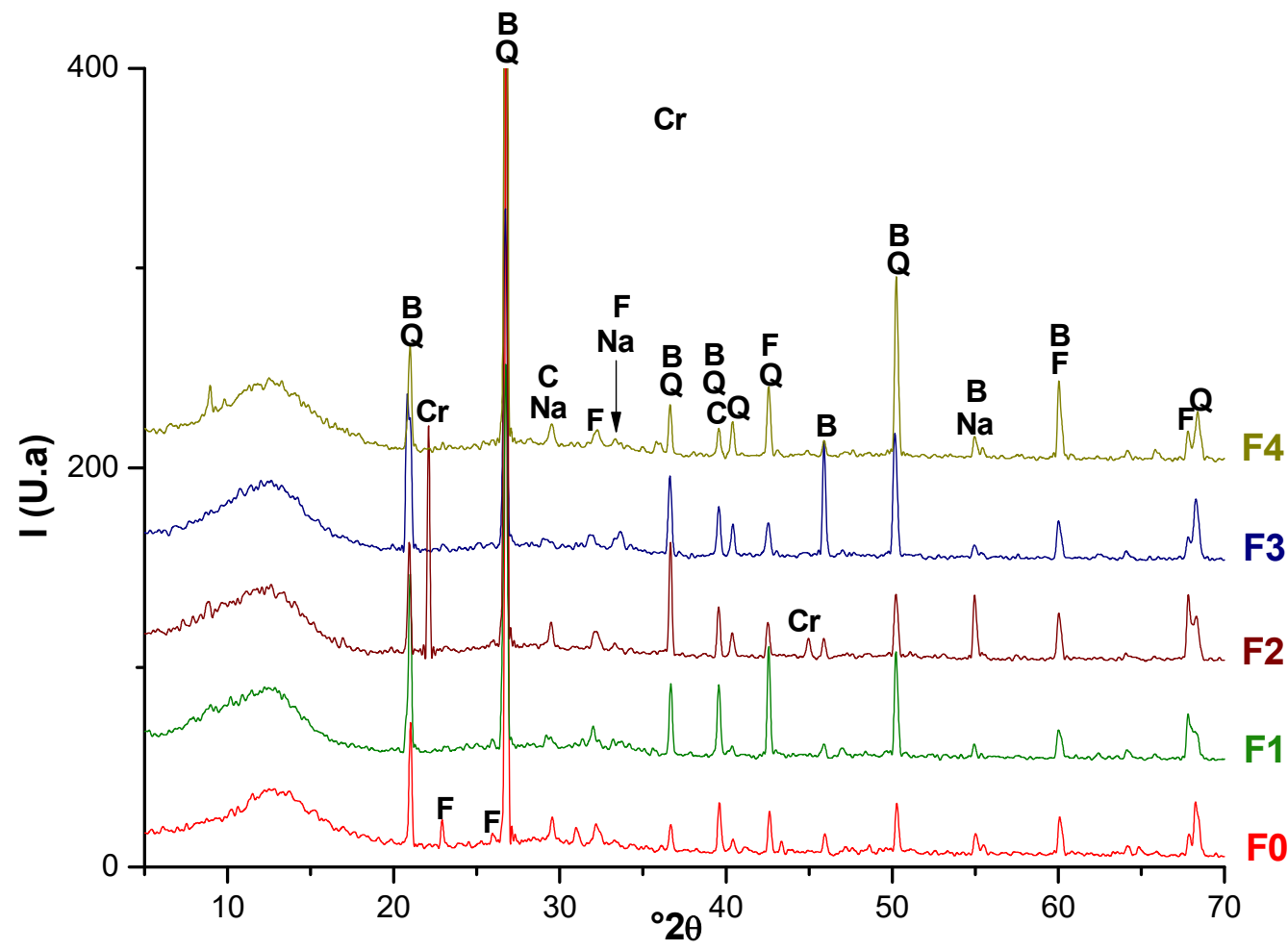

Figure 3. X-ray diffraction patterns of fused phosphate sludge using 10 and $20 \%$ of $\mathrm{NaOH}$ at temperatures of 550 and $800{ }^{\circ} \mathrm{C}$. F: Fluorapatite (PDF \# 00-002-0845); Q: Quartz (PDF \# 96-101-1177); C: Calcite (PDF \# 01-072-1651); Na: Sodium calcium silicate (PDF \# 01-079-1086); B: Berlinite (PDF \# 00-003-0447); Cr: Cristobalite (PDF \# 96-900-1580)

The SEM images of the geopolymer samples F1 and F2 (see Figure 4) shows the presence of unreacted particles whiting the geopolymeric matrix. For the samples using phosphate sludge fused at $550{ }^{\circ} \mathrm{C}$ these unreacted particles are embedded in the geopolymeric matrix and plays a barrier function against cracks propagation (see Figure 4a). In contrast, a separated layer of unreacted particles can be observed in the top of the geopolymer binder (see Figure 4b) which approve the higher compressive strength of the samples fused at low fusion temperature $\left(550{ }^{\circ} \mathrm{C}\right)$ in comparison with the one fused at $800^{\circ} \mathrm{C}$.
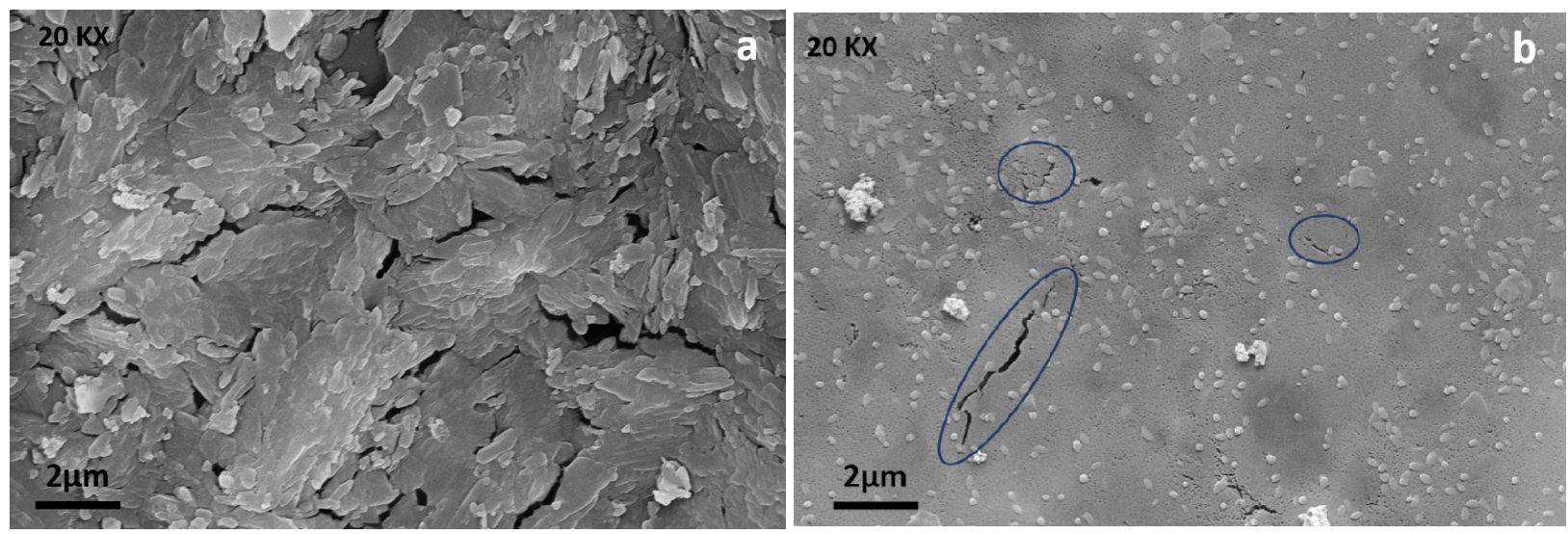

Figure 4. SEM images of fused phosphate sludge based geopolymer mortars: (a) F1; (b) F2 
The EDX analysis confirms the previous finding showing that the Si and Al content of the sample F2 fused at $550{ }^{\circ} \mathrm{C}$ is higher than for the sample $\mathrm{F} 1$. In addition, the EDX analysis of F1 sample shows an agglomeration of unreacted particles in the top of the geopolymer binder (see Figure $5 \mathrm{~b}$ and Table 3 ).
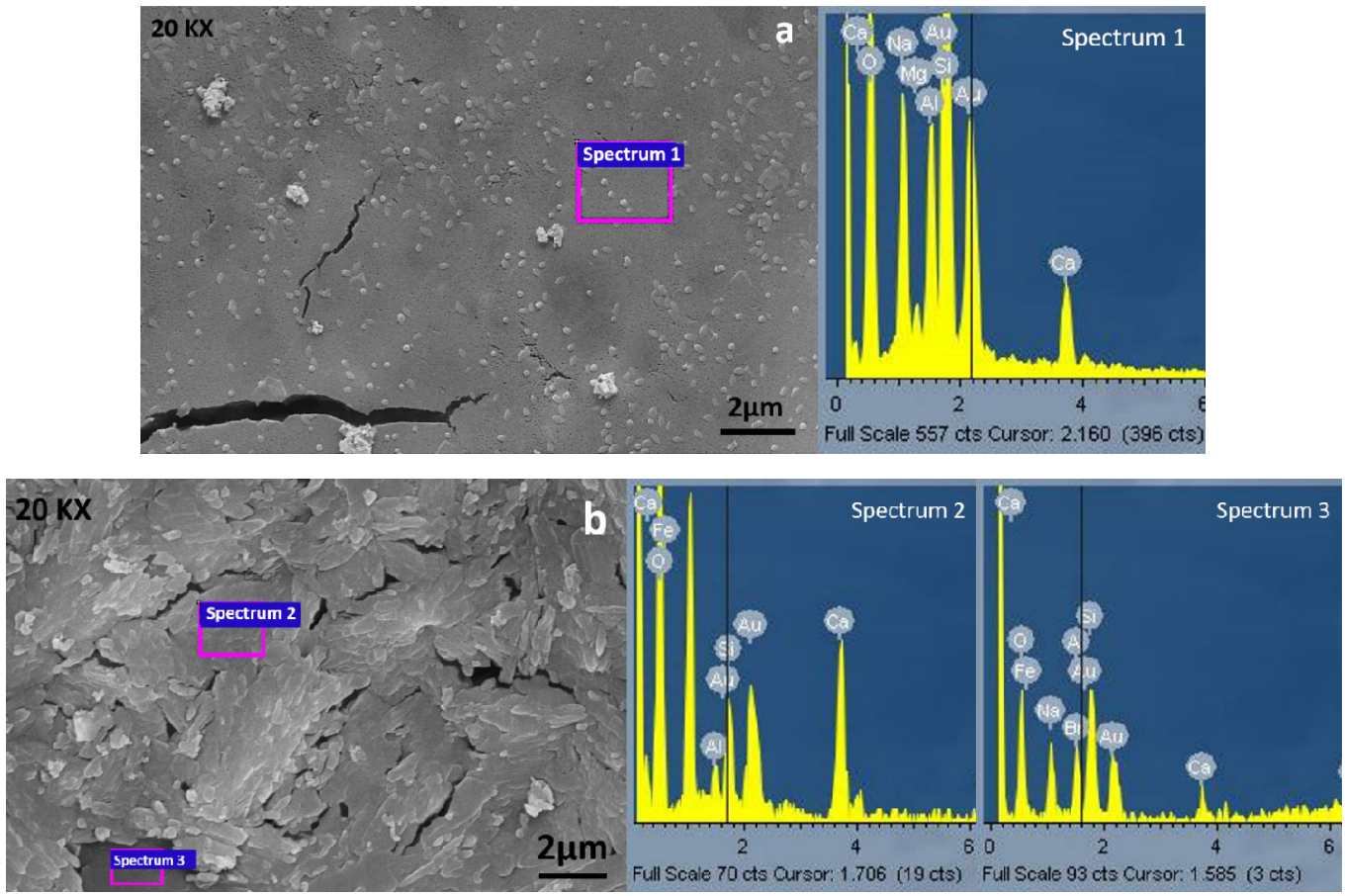

Figure 5. SEM/EDS micrographs of fused phosphate sludge based geopolymer mortars: (a) F2; (b) F1

Table 3. EDX chemical composition of spectrum 1, 2 and 3 of F1 and F2 samples

\begin{tabular}{|c|c|c|c|c|c|c|}
\hline Spectrum & $\mathrm{Si}$ & $\mathrm{Al}$ & $\mathrm{Ca}$ & $\mathrm{Na}$ & $\mathrm{Si} / \mathrm{Al}$ & $\mathrm{Na} / \mathrm{Al}$ \\
\hline Spectrum 1 & 18.53 & 7.33 & 3.38 & 8.59 & 2.53 & 1.17 \\
\hline Spectrum 2 & 4.22 & 1.64 & 11.11 & 3.92 & 2.57 & 2.39 \\
\hline Spectrum 3 & 12.17 & 5.95 & 3.36 & 10.49 & 2.05 & 1.76 \\
\hline
\end{tabular}

The thermal resistance of the geopolymer samples was evaluated by measuring the compressive strength after exposure to different elevated temperatures and a thermal shock. The results of compressive strength evolution are summarized in Figure 6. all samples showed the same evolution trend regardless of the $\mathrm{NaOH}$ content or the temperature of fusion. However, different behaviors were observed depending on the temperature of treatment. Treatment at

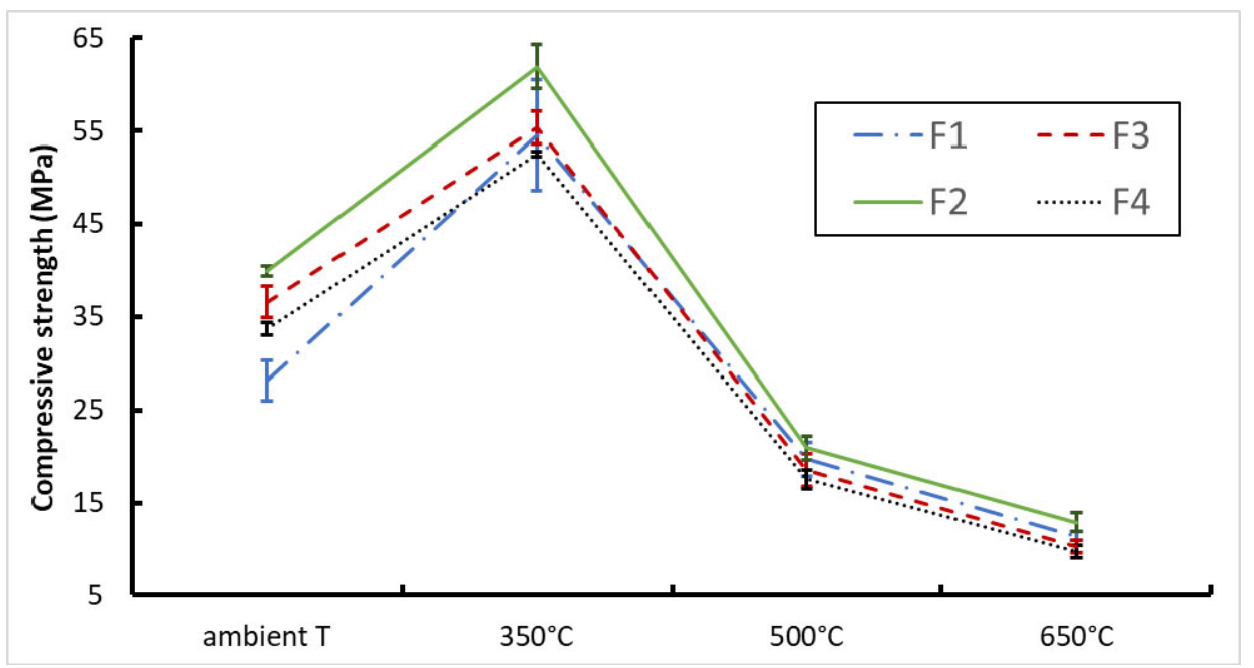

Figure 6. Variation of the geopolymer mortars compressive strength before and after heat treatment at several temperatures $\left(350,500\right.$ and $\left.650{ }^{\circ} \mathrm{C}\right)$ 
$350{ }^{\circ} \mathrm{C}$ induce an increase of the geopolymer's compressive strength, which is attributed to the completion of the geopolymerization reaction and the participation of the unreacted particles. Nevertheless, treatment at higher temperatures result in a large compressive strength decline. The treatment at elevated temperatures up to $500{ }^{\circ} \mathrm{C}$ induce cracks and an increase of porosity as shown in Figure 7. It is clearly noticed from the SEM images of the geopolymer samples that the unreacted particles were partially or completely dissolved in the matrix after thermal treatment. Overall, the optimum mixture prepared using phosphate sludge fused at $550{ }^{\circ} \mathrm{C}$ and $10 \mathrm{wt} \%$ preserved a compressive strength of $12.86 \mathrm{MPa}$ after exposure to $650^{\circ} \mathrm{C}$ for $4 \mathrm{~h}$.
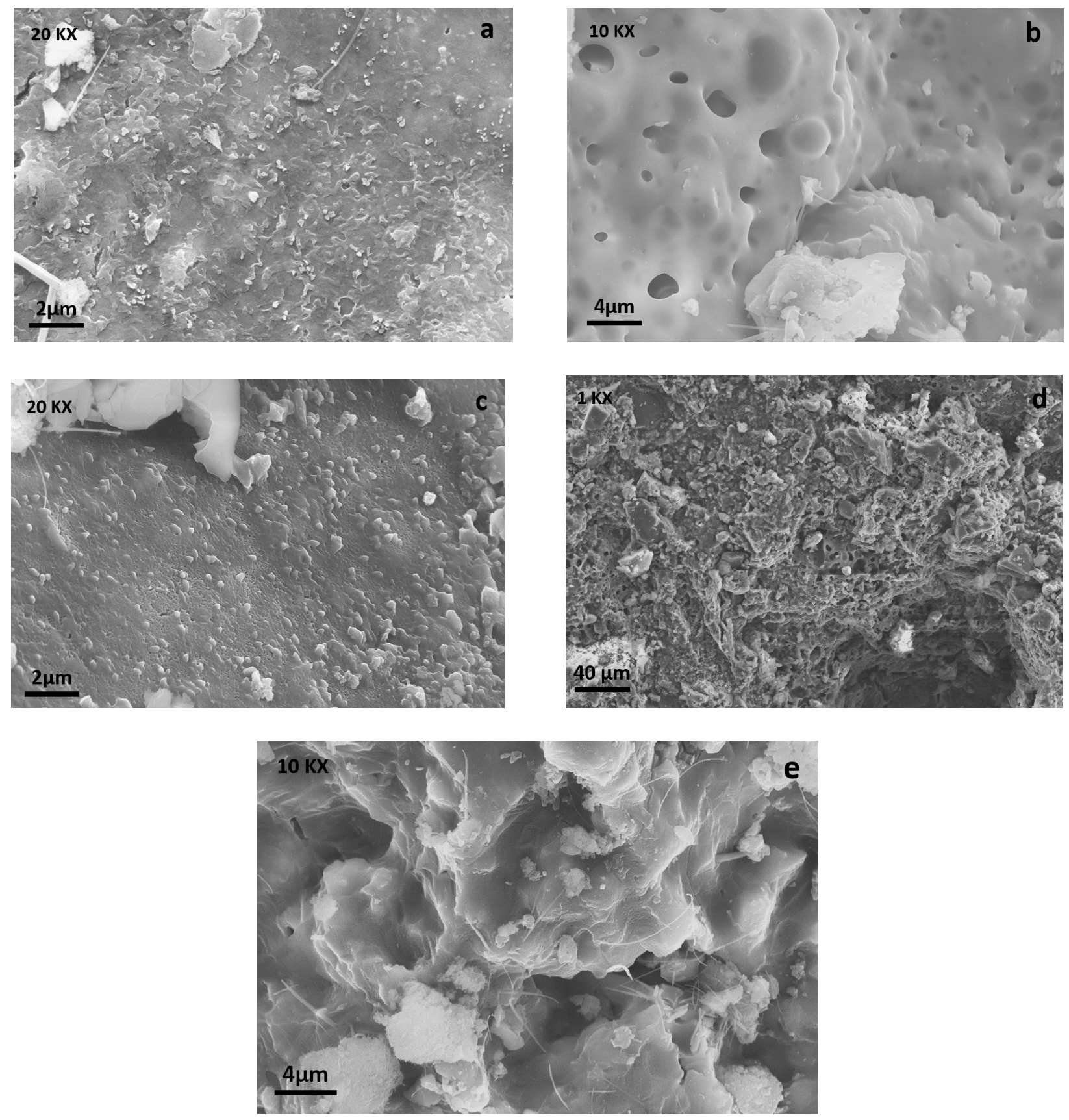

Figure 7. SEM images of fused phosphate sludge based geopolymers after exposure to high temperatures: (a) F1 exposed to $500{ }^{\circ} \mathrm{C}$; (b) F1 exposed to $650{ }^{\circ} \mathrm{C}$; (c) $\mathrm{F} 2$ treated at $500{ }^{\circ} \mathrm{C}$; (d) and (e): $\mathrm{F} 2$ treated at $650{ }^{\circ} \mathrm{C}$ with different magnifications

\section{Conclusions}

The present paper investigated the feasibility of using the alkaline fusion method for the activation of phosphate mine tailing mainly phosphate sludge to produce geopolymer mortars and studied the mechanical behavior of the resulted geopolymers after exposure to elevated temperature. 
The results showed that the temperature of fusion and the $\mathrm{NaOH}$ content are strongly correlated and has a significative impact on the final properties of the geopolymers. The optimum fusion condition was found at $10 \mathrm{wt} \%$ of $\mathrm{NaOH}$ and $550{ }^{\circ} \mathrm{C}$ exhibiting the higher compressive strength. Furthermore, the fusion at $550{ }^{\circ} \mathrm{C}$ leads to more homogenous paste, where the unreacted particles are surrounded by the geopolymeric matrix while a treatment at $800^{\circ} \mathrm{C}$ induce the formation of layers of the agglomerated unreacted particle in the top of the geopolymer binder which weakens the samples. The compressive strength results after exposure to high temperatures showed that a treatment at $350{ }^{\circ} \mathrm{C}$ was beneficial while a treatment at higher temperatures induce a decrease of the geopolymers strength due to the formation of cracks. In essence, geopolymer mortars with good mechanical properties up to 40 $\mathrm{MPa}$ were synthesized from fused phosphate sludge at $550{ }^{\circ} \mathrm{C}$ using $10 \%$ of $\mathrm{NaOH}$. In addition, the geopolymer mortars conserved their structural integrity after exposure to $650{ }^{\circ} \mathrm{C}$.

\section{References}

Ahmari, S., Parameswaran, K., \& Zhang, L. (2014). Alkali activation of copper mine tailings and low-calcium flash-furnace Copper smelter slag. Journal of Materials in Civil Engineering, 27(6), 04014193. https://doi.org/10.1061/(ASCE)MT.1943-5533.0001159

Ahmari, S., \& Zhang, L. (2013). Durability and leaching behavior of mine tailings-based geopolymer bricks. Construction and Building Materials, 44, 743-750. https://doi.org/10.1016/j.conbuildmat.2013.03.075

Caballero, E., Sánchez, W., \& Ríos, C. A. (2014). Synthesis of geopolymers from the alkaline activation of gold mining waste. Engineering and Competitiveness, 16(1), 317-330. https://doi.org/10.25100/iyc.v16i1.3735

Hairi, S. N. M., Jameson, G. N. L., Rogers, J. J., \& MacKenzie, K. J. D. (2015). Synthesis and properties of inorganic polymers (geopolymers) derived from Bayer process residue (red mud) and bauxite. Journal of Materials Science, 50(23), 7713-7724. https://doi.org/10.1007/s10853-015-9338-9

Jiao, X., Zhang, Y., \& Chen, T. (2013). Thermal stability of a silica-rich vanadium tailing based geopolymer. Construction and Building Materials, 38, 43-47. https://doi.org/10.1016/j.conbuildmat.2012.06.076

Ke, X., Bernal, S. A., Ye, N., Provis, J. L., \& Yang, J. (2015). One-part geopolymers based on thermally treated red Mud/NaOH blends. Journal of the American Ceramic Society, 98(1), 5-11. https://doi.org/10.1111/jace.13231

Kouamo Tchakoute, H., Elimbi, A., Diffo Kenne, B. B., Mbey, J. A., \& Njopwouo, D. (2013). Synthesis of geopolymers from volcanic ash via the alkaline fusion method: Effect of $\mathrm{Al}_{2} \mathrm{O}_{3} / \mathrm{Na}_{2} \mathrm{O}$ molar ratio of soda-volcanic ash. Ceramics International, 39(1), 269-276. https://doi.org/10.1016/j.ceramint.2012.06.021

Kuranchie, F. A., Shukla, S. K., \& Habibi, D. (2016). Utilisation of iron ore mine tailings for the production of geopolymer bricks. International Journal of Mining, Reclamation and Environment, 30(2), 92-114. https://doi.org/10.1080/17480930.2014.993834

Moukannaa, S., Loutou, M., Benzaazoua, M., Vitola, L., Alami, J., \& Hakkou, R. (2018). Recycling of phosphate mine tailings for the production of geopolymers. Journal of Cleaner Production, 185, 891-903. https://doi.org/10.1016/j.jclepro.2018.03.094

Naghsh, M., \& Shams, K. (2017). Synthesis of a kaolin-based geopolymer using a novel fusion method and its application in effective water softening. Applied Clay Science, 146, 238-245. https://doi.org/10.1016/j.clay.2017.06.008

Pacheco-Torgal, F., Castro-Gomes, J. P., \& Jalali, S. (2008). Investigations on mix design of tungsten mine waste geopolymeric binder. Construction and Building Materials, 22(9), 1939-1949. https://doi.org/10.1016/j.conbuildmat.2007.07.015

Perná, I., Hanzlíček, T., \& Šupová, M. (2014). The identification of geopolymer affinity in specific cases of clay materials. Applied Clay Science, 102, 213-219. https://doi.org/10.1016/j.clay.2014.09.042

Tchadjie, L., \& Ekolu, S. (2017). Enhancing the reactivity of aluminosilicate materials toward geopolymer synthesis. Journal of Materials Science, 53(7), 4709-4733. https://doi.org/10.1007/s10853-017-1907-7

Tchadjié, L. N., Djobo, J. N. Y., Ranjbar, N., Tchakouté, H. K., Kenne, B. B. D., Elimbi, A., \& Njopwouo, D. (2015). Potential of using granite waste as raw material for geopolymer synthesis. Ceramics International, 42(2), 3046-3055. https://doi.org/10.1016/j.ceramint.2015.10.091

Xu, H., Li, Q., Shen, L., Zhang, M., \& Zhai, J. (2010). Low-reactive circulating fluidized bed combustion (CFBC) fly ashes as source material for geopolymer synthesis. Waste Management, 30(1), 57-62. https://doi.org/10.1016/j.wasman.2009.09.014

Zivica, V., Palou, M. T., \& Bágel', T. I. L. (2014). High strength metahalloysite based geopolymer. Composites Part B: Engineering, 57, 155-165. https://doi.org/10.1016/j.compositesb.2013.09.034 